\title{
Most Common Formal Grammatical Errors Committed by Authors
}

\author{
Anthony J. Onwuegbuzie (Corresponding author) \\ Department of Educational Leadership and Counseling, Sam Houston State University \\ Box 2119, Huntsville, Texas 77341-2119, USA \\ $\&$ \\ Distinguished Visiting Professor, Faculty of Education, University of Johannesburg \\ B-Ring 433, Kingsway Campus, Auckland Park, South Africa \\ E-mail: tonyonwuegbuzie@aol.com
}

\begin{abstract}
Received: February 26, 2017 Accepted: April 2, 2017 Published: April 5, 2017
doi:10.5296/jei.v3i1.10839 URL: http://dx.doi.org/10.5296/jei.v3i1.10839
\end{abstract}

\begin{abstract}
Empirical evidence has been provided about the importance of avoiding American Psychological Association (APA) errors in the abstract, body, reference list, and table sections of empirical research articles. Specifically, authors are significantly more likely to have their manuscripts rejected for publication if they commit numerous APA violations - and, thus, do not write with discipline - in these sections. In addition to adhering to APA, writing with discipline also includes avoiding what I call formal grammatical errors. Thus, in this study, I analyzed formal grammatical errors committed in 117 manuscripts submitted to the journal Research in the Schools over a 6-year period. Among other results, I identified the 35 most common formal grammatical errors. The use of colloquial words/phrases (e.g., "the author did a good job") (76.1\%) represented the most common grammatical error. Further, I identified a link between the number of grammatical errors and the subsequent disposition of a manuscript (i.e., accept vs. revise and resubmit vs. reject). Finally, I identified the formal grammatical errors that best predicted whether or not a manuscript was rejected by the editor. I contend that an efficient way for authors to learn how to write with discipline is to focus initially on these most common formal grammatical errors. Further, I contend that these errors provide useful starting points for persons who teach scholarly writing. Finally, authors of the APA Publication Manual might use this information to determine which grammatical rules and guidelines to emphasize.
\end{abstract}


Keywords: Grammar, Grammatical errors, Research in the Schools, Writing with discipline, Manuscript rejection, Manuscript acceptance

\section{Introduction}

Writing scholarly works poorly typically has negative consequences. For example, with respect to manuscripts written for journals, more than a decade ago, Onwuegbuzie and Daniel (2005) documented that manuscripts submitted to Research in the Schools, a nationally/internationally refereed journal, that are poorly written overall are approximately 12 times more likely to be rejected, on average, than are well-written manuscripts. As a result of this finding, Onwuegbuzie and colleagues subsequently have written a series of works (e.g., articles, book chapters, book) in which they have deconstructed the writing process. Through these works, they have demonstrated the importance of writing with discipline when writing dissertations/theses and manuscripts for consideration for publication in journals. In particular, these authors have made evident the importance of avoiding violations to the American Psychological Association (APA) style guide (APA, 2010) in the abstract (Hahs-Vaughn, Onwuegbuzie, Slate, \& Frels, 2009) and the body of the manuscript (Onwuegbuzie, Combs, Slate, \& Frels, 2010), as well as in the reference list (Onwuegbuzie, Combs, Frels, \& Slate, 2011; Onwuegbuzie, Frels, \& Slate, 2010; Onwuegbuzie, Hwang, Combs, \& Slate, 2012; Onwuegbuzie, Hwang, Frels, \& Slate, 2011; Onwuegbuzie, Waytowich, \& Jiao, 2006; Waytowich, Onwuegbuzie, \& Jiao, 2006) and table (Frels, Onwuegbuzie, \& Slate, 2010a) sections of empirical and non-empirical (e.g., methodological, conceptual, theoretical) manuscripts submitted to a journal for review for possible publication. Further, Onwuegbuzie, Mallette, Slate, and Hwang (2013) provided evidence that the readability of the manuscript is an important predictor of the quality of a manuscript. Specifically, using two popularized and easily accessible readability formulas, namely, the Flesch Reading Ease (RE) and Flesch-Kincaid Grade Level (GL), Onwuegbuzie et al. (2013) reported that (a) manuscripts with Flesch RE scores between 0 and 30 were 1.64 more times less likely to be rejected than were manuscripts with Flesch RE scores greater than 30, and (b) manuscripts with Flesch-Kincaid GL scores of 16 and above were 4.55 times less likely to be rejected than were manuscripts with Flesch-Kincaid GL scores less than 16. Most recently, in an investigation of the role of link (i.e., transition) words/phrases, Onwuegbuzie (2016) not only conceptualized 12 dimensions of link words/phrases and identified the most common link words/phrases, but also documented that manuscripts submitted to a journal for review for possible publication were statistically significantly and practically significantly less likely to be rejected if they contained one or more link words/phrases that were classified as representing the dimensions labelled as (a) add information/provide similarity (e.g., Further, Moreover) - 1.75 times less likely to be rejected; (b) narration (e.g., Initially, Suddenly) - 1.32 times less likely to be rejected; and (c) provide an emphasis (e.g., Specifically, Particularly) -1.75 times less likely to be rejected. Based on these findings, Onwuegbuzie (2016) concluded that

a plausible explanation resides in the complexity of scholarly articles-regardless of genre (i.e., quantitative research, qualitative research, mixed research). Because of this complexity, it is important for authors to use link words/phrases in a way that they 
provide appropriate transitions between sentences and between paragraphs-which serve as proxies for assumptions, ideas, beliefs, propositions, theories, schemas, models, hypotheses, and the like. This use of link words/phrases-especially those associated with Add information/provide similarity, Narration, and Provide an emphasis - then, maximize the coherence of a manuscript, which, in turn, make it easier for readers in general and journal reviewers in particular to follow the author's logic of argumentation. (p. 327)

Simply put, findings from these series of works have demonstrated that authors are statistically and practically significantly more likely to have their manuscripts rejected for publication if they do not "write with discipline" (Onwuegbuzie \& Combs, 2009, p. 116). However, adhering to APA style in various sections of a manuscript and to readability guidelines and link word/phrase conventions are not the only pathways to writing with discipline. In fact, when writing with discipline, I contend that it is also important for authors to avoid omitting grammatical errors. Indeed, as an editor of three journals, guest editor of several special issues, and reviewer of numerous journals, I have noticed that a common weakness of manuscripts written by beginning writers - and even more experienced writers - is the variety of grammatical errors committed. Unfortunately, committing numerous grammatical errors prevents a manuscript from being maximally coherent, thereby making it more difficult for readers in general and journal reviewers in particular to follow the author's logic of argumentation. However, to date, no researcher empirically has examined the grammatical errors that are committed by authors.

\subsection{Conceptual Framework}

Broadly speaking, a grammatical error-also known as a usage error-refers to any instance of faulty, unconventional, or controversial usage, such as a subject-verb disagreement or an inappropriate verb tense. It should be noted that grammatical errors are distinct from other types of writing errors such as misspellings, typographical errors (i.e., mistakes made in the typing process such as simple duplication, omission, transposition, or substitution of a small number of characters), factual errors (i.e., mistake made in specifying facts), logical fallacies (i.e., errors of reasoning), and faulty punctuation (i.e., "errors in the use of spacing, conventional signs, and certain typographical devices as aids to the understanding and the correct reading, both silently and aloud, of handwritten and printed texts"; Encyclopaedia Britannica, n.d.). Grammatical errors have the potential to impede effective communication.

\subsection{Purpose of Study and Research Questions}

With the aforementioned discussion in mind, the purpose of my study was to examine the prevalence of formal grammatical errors in manuscripts submitted to a journal for consideration for publication. By formal grammatical errors, I am referring to grammatical errors that are pertinent in formal (i.e., scholarly) works. A second purpose was to examine the importance of formal grammatical errors on the quality of empirical manuscripts submitted to a journal for consideration for publication, as indicated by their eventual disposition (i.e., accept vs. revise and resubmit vs. reject). Specifically, the following six research questions were addressed: 
1) What is the prevalence of formal grammatical errors among manuscripts submitted to a journal?

2) What is the relationship between the overall frequency of formal grammatical errors and style guide errors (i.e., APA errors) among manuscripts submitted to a journal?

3) What is the relationship between the overall frequency of formal grammatical errors and citation errors among manuscripts submitted to a journal?

4) What is the relationship between the overall frequency of formal grammatical errors and select demographic characteristics (e.g., number of authors, gender of the lead author, length of manuscript, genre of manuscript) among manuscripts submitted to a journal?

5) What is the relationship between the overall frequency of formal grammatical errors and manuscript disposition among manuscripts submitted to a journal?

6) Which grammatical errors, if any, discriminate manuscripts that are rejected and manuscripts that are not rejected?

\section{Method}

\subsection{Sample Size and Procedures}

To analyze the prevalence and predictability of formal grammatical errors among manuscripts submitted to a journal, I examined 117 manuscripts submitted to RITS over a 6-year period (i.e., 2014-2015). These manuscripts represented approximately $50 \%$ of all manuscripts submitted to this journal over this time frame, which made these findings generalizable at the very least to the population of manuscripts submitted to RITS. The sample size of 117 was selected via an a priori statistical power analysis. Specifically, it represented the sample size needed to detect a moderate multivariate relationship (i.e., discriminant analysis; $f=.28$ ) simultaneously for the dependent measures (i.e., 23 most common grammatical errors committed) between the two groups (i.e., manuscripts that were rejected vs. manuscripts that were not rejected) at the $5 \%$ level of statistical significance and a power of .80 .

For each of the 117 manuscripts submitted to RITS over this time period, I meticulously documented every grammatical error, APA error, and citation error committed by these 117 sets of authors. It took up to 4 hours to identify all the grammatical errors, APA errors, and citation errors contained in a manuscript — representing approximately 468 hours of coding. In addition, I noted several demographic features of the manuscript (e.g., number of authors, gender of first author, length of manuscript, genre of manuscript), as well as the disposition of the manuscript.

Next, I used QDA Miner, Version 4.1.12 (Provalis Research, 2014) to conduct an initial coding of the 117 manuscripts for the formal grammatical errors contained in them, as well as to code characteristics of each manuscript (e.g., genre of manuscript [i.e., qualitative vs. quantitative vs. mixed methods vs. non-empirical]; number of authors, page length, word count), and to conduct a classical content analysis (Berelson, 1952) that determined the prevalence rates; and SPSS to conduct descriptive analyses (e.g., measures of central 
tendency, measures of variability) and univariate analyses (e.g., Pearson $r \mathrm{~s}$ ), as well as a discriminant analysis to determine the predictability of select grammatical errors with respect to manuscript disposition (i.e., accept vs. revise and resubmit vs. reject) among manuscripts submitted to RITS. As such, the data set created was extremely rich.

\subsection{Analysis}

Descriptive statistics (i.e., measures of central tendency) were used to address the first research question (i.e., What is the prevalence of grammatical errors among manuscripts submitted to a journal?). Furthermore, a series of Pearson $r \mathrm{~s}$ was computed to examine the relationship between the number of formal grammatical errors and the number of APA errors committed (Research Question 2), the number of citation errors committed (Research Question 3), and demographic characteristics (e.g., number of authors) (Research Question 4). Also, an analysis of variance was conducted to examine the number of formal grammatical errors as a function of subsequent manuscript disposition (i.e., accept vs. revise and resubmit vs. reject) (Research Question 5). Finally, a discriminant analysis was used to determine which grammatical errors, if any, discriminated manuscripts that were rejected and manuscripts that were not rejected (Research Question 6).

\section{Results and Discussion}

\subsection{Research Question 1. What Is the Prevalence of Formal Grammatical Errors among Manuscripts Submitted to a Journal?}

\subsubsection{Frequency of Individual Formal Grammatical Errors}

Figure 1 presents the 35 most common formal grammatical errors committed by authors who submitted manuscripts to Research in the Schools over the 6-year period. Figure 2 presents these most common grammatical errors that emerged from the analysis, as well as other grammatical errors, alongside an example of the error and the corrected version. Using Cohen's (1988, pp. 180-183) non-linear arcsine transformation and Cohen's $d$ criteria yielded cut-points of $1 \%$ endorsement as representing a small effect size, $7 \%$ endorsement as representing a medium effect size, and $16 \%$ endorsement as representing a large effect size. Thus, in the following sections, I will discuss, in the order of prevalence rate, grammatical errors whose prevalence rate represented a large effect size (i.e., $\geq 16 \%$ ) -which yielded 11 formal grammatical errors.

\subsubsection{Colloquial Words/Phrases}

Figure 1 reveals that the use of colloquial words/phrases, including the use of jargon, was the most common formal grammatical error-committed by more than three fourths (i.e., 76.1\%) of the authors. According to dictionary.com, the word colloquial is defined as "denoting or characterized by informal or conversational idiom or vocabulary," "pertaining to words or expressions more suitable for speech than writing; in informal," and "conversational style" (http://www.dictionary.com/browse/colloquial?s=t). The word colloquial comes from the Latin word colloquy (circa 1751), which means "a conversation" + -al, wherein -al represents

a suffix with the general sense "of the kind of, pertaining to, having the form or character 
of" that named by the stem, occurring in loanwords from Latin (autumnal; natural; pastoral), and productive in English on the Latin model, usually with bases of Latin origin (accidental; seasonal; tribal). (http://www.dictionary.com/browse/-al)

Also, the Latin word colloquium means "speaking together." Interestingly, the authors of APA also admonish the use of colloquial expressions and jargon, as follows:

Colloquial expressions: Avoid colloquial expressions (e.g., write up for report), which diffuse meaning. Approximations of quantity (e.g., quite a large part, practically all, or very $f e w)$ are interpreted differently by different readers or in different contexts. Approximations weaken statements, especially those describing empirical observations.

Jargon: Jargon is the continuous use of a technical vocabulary, even in places where that vocabulary is not relevant. Jargon is also the substitution of a euphemistic phrase for a familiar term (e.g., monetarily felt scarcity for poverty), and you should scrupulously avoid using such jargon. Federal bureaucratic jargon has had the greatest publicity, but scientific jargon also grates on the reader, encumbers the communication of information, and wastes space. (APA, 2010, p. 68) [emphasis in original]

\begin{tabular}{|c|c|c|}
\hline Rank & Grammatical Error & Frequency $(\%)$ \\
\hline 1 & Colloquial words/phrases & 76.1 \\
\hline 2 & Split infinitives & 75.9 \\
\hline 3 & Subject-verb disagreement & 45.7 \\
\hline 4 & Mismatch between possessive pronoun and noun & 43.1 \\
\hline 5 & Use of "may" instead of "might" & 33.6 \\
\hline 6 & Use of "between" instead of "among" & 26.7 \\
\hline 7 & Paragraphs containing less than three sentences & 26.1 \\
\hline 8 & Adverb used to begin sentence without a comma & 25.9 \\
\hline 9 & Use of contractions (e.g., “don't”) & 19.0 \\
\hline 10 & Misspelled words & 18.3 \\
\hline 11 & Incorrect use of possessive nouns & 17.2 \\
\hline 12 & Unparallel construction & 14.7 \\
\hline 13 & Preposition ending sentence & 13.0 \\
\hline 14 & Incorrect use of the word "include"/"includes"/"included" & 11.2 \\
\hline 15 & Nonuse of apostrophe in possessive case & 10.3 \\
\hline 16 & Anthropomorphisms used & 5.9 \\
\hline 17 & A figure beginning a sentence (e.g., "100 people completed the survey") & 5.1 \\
\hline
\end{tabular}




\begin{tabular}{|l|l|l|}
\hline 18 & Comma used instead of semi-colon & 4.2 \\
\hline 19 & Incorrect use of the word "feel" & 4.2 \\
\hline 20 & Incorrect use of tense & 4.2 \\
\hline 21 & Sentence ending with no period & 4.2 \\
\hline 22 & Hyphens omitted from words that should be hyphenated (e.g., "self-esteem") & 4.2 \\
\hline 23 & Use of the word "if" instead of "whether" & 3.5 \\
\hline 24 & Use of the word "comprised" & 2.6 \\
\hline 25 & Mismatch between indefinite article and noun (e.g., "a higher scores") & 2.6 \\
\hline 26 & Quotation beginning a sentence & 2.6 \\
\hline 27 & Incorrect use of verb (e.g., "found" instead of "theorized") & 2.6 \\
\hline 28 & Missing words & 1.7 \\
\hline 29 & Use of the word “quote' instead of "quotation" & 0.9 \\
\hline 30 & Incorrect use of preposition (e.g., "the school for which he belonged") & 0.9 \\
\hline 31 & Nonuse of the conjunction that to introduce a noun clause & 0.9 \\
\hline 32 & Mismatch between indefinite article and the adjective that proceeds it & 0.9 \\
\hline 33 & Repeating words (e.g., "the the") & 0.9 \\
\hline 34 & Use of the second person instead of the third person & 0.9 \\
\hline 35 & Use of the phrase "right" and/or “wrong" instead of "correct" or "incorrect" & 0.9 \\
\hline & & \\
\hline
\end{tabular}

Figure 1 . The 35 most common formal grammatical errors committed by authors who submitted manuscripts to Research in the Schools over a 6-year period

\begin{tabular}{|l|l|l|}
\hline Grammatical Error & Example of Error & Corrected Version \\
\hline $\begin{array}{l}\text { Nonuse of the apostrophe for } \\
\text { possessive nouns }\end{array}$ & $\begin{array}{l}\text { These authors findings } \\
\text { These author's findings } \\
\text { Each authors' findings } \\
\text { Frels' (2014) study ... }\end{array}$ & $\begin{array}{l}\text { These authors' findings } \\
\text { These authors' findings } \\
\text { Each author's findings } \\
\text { Frels's (2014) study ... }\end{array}$ \\
\hline $\begin{array}{l}\text { Mismatch between possessive } \\
\text { pronouns and nouns }\end{array}$ & $\begin{array}{l}\text { Several researchers have } \\
\text { developed their own instrument }\end{array}$ & $\begin{array}{l}\text { Several researchers have developed } \\
\text { their own instruments }\end{array}$ \\
\hline $\begin{array}{l}\text { Mismatch between } \\
\text { Indefinite article and noun }\end{array}$ & $\begin{array}{l}\text { Some researchers have reported a } \\
\text { higher scores }\end{array}$ & $\begin{array}{l}\text { Some researchers have reported } \\
\text { higher scores }\end{array}$ \\
\hline Colloquial expressions & The researcher ran her analysis & The researcher conducted her analysis \\
\hline Using may instead of might & $\begin{array}{l}\text { These findings may have } \\
\text { implications for teachers }\end{array}$ & $\begin{array}{l}\text { These findings might have } \\
\text { implications for teachers }\end{array}$ \\
\hline
\end{tabular}




\begin{tabular}{|c|c|c|}
\hline Contractions & $\begin{array}{l}\text { The findings didn't support the } \\
\text { theory }\end{array}$ & $\begin{array}{l}\text { The findings did not support the } \\
\text { theory }\end{array}$ \\
\hline Anthropomorphism & The study found & $\begin{array}{l}\text { The study revealed } \\
\text { The researcher found }\end{array}$ \\
\hline $\begin{array}{l}\text { Split infinitives unnecessarily } \\
\text { being used. }\end{array}$ & $\begin{array}{l}\text { The number of mixed research } \\
\text { studies in this area has continued } \\
\text { to steadily increase }\end{array}$ & $\begin{array}{l}\text { The number of mixed research studies } \\
\text { in this area steadily has continued to } \\
\text { increase }\end{array}$ \\
\hline $\begin{array}{l}\text { The word "if" often is } \\
\text { mistakenly used as a } \\
\text { substitute for the word } \\
\text { "whether." }\end{array}$ & $\begin{array}{l}\text { Researchers have not decided if } \\
\text { this interpretation represents the } \\
\text { most viable explanation }\end{array}$ & $\begin{array}{l}\text { Researchers have not decided whether } \\
\text { this interpretation represents the most } \\
\text { viable explanation }\end{array}$ \\
\hline $\begin{array}{l}\text { Between being used when } \\
\text { more than two elements are } \\
\text { involved }\end{array}$ & $\begin{array}{l}\text { Debates have emerged between } \\
\text { quantitative, qualitative, and } \\
\text { mixed researchers }\end{array}$ & $\begin{array}{l}\text { Debates have emerged among } \\
\text { quantitative, qualitative, and mixed } \\
\text { researchers }\end{array}$ \\
\hline $\begin{array}{l}\text { The words feel, think, and } \\
\text { believe being used } \\
\text { interchangeably }\end{array}$ & $\begin{array}{l}\text { The researcher feels that this is an } \\
\text { important finding }\end{array}$ & $\begin{array}{l}\text { The researcher thinks that this is an } \\
\text { important finding }\end{array}$ \\
\hline Using the phrase comprised of & $\begin{array}{l}\text { The sample comprised of both } \\
\text { teachers and students }\end{array}$ & $\begin{array}{l}\text { The sample contained/consisted of } \\
\text { both teachers and students }\end{array}$ \\
\hline Subject verb disagreement & Data is & Data are \\
\hline $\begin{array}{l}\text { The word include(s) or } \\
\text { included being used when the } \\
\text { list involved is exhaustive }\end{array}$ & $\begin{array}{l}\text { The sample included } 100 \text { males } \\
\text { and } 100 \text { females }\end{array}$ & $\begin{array}{l}\text { The sample comprised } 100 \text { males and } \\
100 \text { females }\end{array}$ \\
\hline $\begin{array}{l}\text { Not recognizing that } \\
\text { words such as "Thus" and } \\
\text { "Therefore" indicate a } \\
\text { conditional action, whereas } \\
\text { the word "Thereby" } \\
\text { represents a process }\end{array}$ & $\begin{array}{l}\text { Two participants dropped out of } \\
\text { the study, therefore reducing the } \\
\text { sample size to } 98 \\
\text { Two participants dropped out of } \\
\text { the study; thereby, the sample size } \\
\text { was reduced to } 98\end{array}$ & $\begin{array}{l}\text { Two participants dropped out of the } \\
\text { study, thereby reducing the sample } \\
\text { size to } 98 \\
\text { Two participants dropped out of the } \\
\text { study; therefore, the sample size was } \\
\text { reduced to } 98\end{array}$ \\
\hline $\begin{array}{l}\text { While not only being used to } \\
\text { link events occurring } \\
\text { simultaneously }\end{array}$ & $\begin{array}{l}\text { While these findings are unusual, } \\
\text { they are not unique } \\
\text { The experimental group members } \\
\text { were mostly male, while the } \\
\text { control group members were } \\
\text { mostly female }\end{array}$ & $\begin{array}{l}\text { Although these findings are unusual, } \\
\text { they are not unique } \\
\text { The experimental group members } \\
\text { were mostly male, whereas the control } \\
\text { group members were mostly female }\end{array}$ \\
\hline $\begin{array}{l}\text { The word since not referring } \\
\text { strictly to time }\end{array}$ & $\begin{array}{l}\text { Causality could not be assumed } \\
\text { since the research design was } \\
\text { correlational }\end{array}$ & $\begin{array}{l}\text { Causality could not be assumed } \\
\text { because the research design was } \\
\text { correlational }\end{array}$ \\
\hline
\end{tabular}




\begin{tabular}{|c|c|c|}
\hline $\begin{array}{l}\text { The word that not only being } \\
\text { used for restrictive clauses } \\
\text { and the word which not only } \\
\text { being used for nonrestrictive } \\
\text { clauses (set off with commas) }\end{array}$ & $\begin{array}{l}\text { The findings which were the most } \\
\text { compelling arose from the } \\
\text { qualitative phase } \\
\text { The findings, that were collected } \\
\text { during the qualitative phase, were } \\
\text { very compelling }\end{array}$ & $\begin{array}{l}\text { The findings that were the most } \\
\text { compelling arose from the qualitative } \\
\text { phase } \\
\text { The findings, which were collected } \\
\text { during the qualitative phase, were } \\
\text { very compelling }\end{array}$ \\
\hline $\begin{array}{l}\text { The word who not being used } \\
\text { for human beings }\end{array}$ & $\begin{array}{l}\text { The researchers that used this } \\
\text { technique were in the majority }\end{array}$ & $\begin{array}{l}\text { The researchers who used this } \\
\text { technique were in the majority }\end{array}$ \\
\hline $\begin{array}{l}\text { The word Caucasian being } \\
\text { used }\end{array}$ & $\begin{array}{l}\text { The sample comprised } 250 \\
\text { Caucasian students }\end{array}$ & $\begin{array}{l}\text { The sample comprised } 250 \text { White } \\
\text { students }\end{array}$ \\
\hline $\begin{array}{l}\text { Mismatch between the subject } \\
\text { and plural pronoun used }\end{array}$ & $\begin{array}{l}\text { The researcher must ask } \\
\text { themselves }\end{array}$ & Researchers must ask themselves \\
\hline $\begin{array}{l}\text { The words This and These } \\
\text { being used as stand-alone } \\
\text { pronouns }\end{array}$ & $\begin{array}{l}\text { This demands attention } \\
\text { These have implications for } \\
\text { doctors }\end{array}$ & $\begin{array}{l}\text { This gap in the literature demands } \\
\text { attention } \\
\text { These findings have implications for } \\
\text { doctors }\end{array}$ \\
\hline
\end{tabular}

Figure 2. Select formal grammatical errors and words/phrases that reduce clarity

The problem with using colloquial words/phrases is that not only does their use typically lack descriptive precision but also its meaning can end up being lost in translation. An example of a colloquial phrase is as follows: "The researcher ran the analysis." For an appropriate choice of verb, I refer authors to the work of Frels, Onwuegbuzie, and Slate (2010b). These authors used an iterative process and a priori technique (Constas, 1992) to identify common verbs used in scholarly works. After the data (i.e., verbs compiled through readings) had been collected, they used an a posteriori technique - namely, constant comparison technique - to categorize and to name the emergent categories. Sources for their categorization included their own experiences with the writing process and numerous articles that they had examined over the period of months prior to writing their article. Via their iterative process, these authors repeated the steps of selecting, coding, and categorizing verbs until they differentiated their selected verbs according to general meaning and appropriate use in academic discourse. Subsequently, they conducted a keywords-in-context (KWIC) analysis (Fielding \& Lee, 1998; Leech \& Onwuegbuzie, 2007, 2008, 2011) to examine how verbs were used in context with other words. This analytical process yielded 178 verbs that they sorted into 15 categories and five typologies. Table 1 represents one of Frels et al.'s (2010b) typologies, namely, verbs representing knowledge or action for scholarly writing. The other four verb typologies were verbs representing statements for scholarly writing, verbs representing cognition for scholarly writing, strength of the verb and variation of meaning, and categorical use of verbs (primary and secondary) for academic discourse. Thus, because the verb (i.e., "ran") involved in the colloquial phrase, "The researcher ran the analysis," represents a procedural verb, the verb "conducted" likely is the most appropriate (e.g., 
accurate, meaningful, translatable) verb. In other words, it would be more formal and clearer if this phrase is reworded to a phrase such as "The researcher conducted the analysis." Moreover, the use of the verb "ran," in this context, is not accurately translatable to another language. As an example, translating the phrase "The researcher ran the analysis" into Spanish yields the following phrase:

El investigador se ejecutó el análisis

And translating this Spanish phrase back directly into English (i.e., back translation; Pym, 2010) yields the following phrase:

The researcher analysis was carried out

Already this phrase has lost meaning. Now, translating this latter phrase back directly into Spanish yields the following phrase:

El investigador se llevó a cabo análisis

This Spanish phrase yields the following English phrase:

The researcher conducted analysis

In turn, this English phrase yields the following Spanish phrase:

El investigador realizó un análisis

In turn, this Spanish phrase yields the following English phrase:

The researcher conducted an analysis

And it is not until the English phrase "The researcher conducted an analysis" is established that stability is reached between this English phrase and the Spanish translation "El investigador realizó un análisis." That is, it takes three rounds of back translation before an English phrase is determined that has the same meaning (i.e., is synonymous) as the Spanish phrase. However, not only were the intermediate English phrases (e.g., "The researcher analysis was carried out") far removed from the original colloquial phrase (i.e., "The researcher ran the analysis"), but also the final back-translated English phrase ("The researcher conducted an analysis") does not have the same meaning as does the original colloquial phrase (i.e., "The researcher ran the analysis") because the word "an" before the word "analysis" in the triple back-translated phrase could refer to any analysis, whereas the use of the word "the" before the word "analysis" in the original colloquial phrase refers to a specific analysis - specifically, the actual analysis conducted by this researcher. 
Table 1. Typology of verbs representing knowledge or action for scholarly writing

\begin{tabular}{|c|c|c|c|c|}
\hline $\begin{array}{l}\text { Evidence-Based/ } \\
\text { Data Driven Verbs }\end{array}$ & Procedural Verbs & Visual Verbs & Direct Object Verbs & Creation Verbs \\
\hline found & adapted & exhibited & gathered & crafted \\
\hline embarked & analyzed & displayed & collected & originated \\
\hline encountered & examined & graphed & composed & generated \\
\hline noted & performed & illustrated & sampled & synthesized \\
\hline revealed & conducted & presented & randomized & engendered \\
\hline detected & undertook & mapped & chose & stimulated \\
\hline tested & consulted & depicted & selected & instituted \\
\hline discovered & scrutinized & represented & elected & constituted \\
\hline traced & consented & elucidated & developed & theorized \\
\hline observed & originated & & contrived & established \\
\hline documented & composed & & modeled & developed \\
\hline experienced & produced & & provided & maintained \\
\hline uncovered & conceptualized & & procured & devised \\
\hline extracted & consulted & & preferred & invented \\
\hline demonstrated & reviewed & & adopted & devised \\
\hline showed & evaluated & & provided & expanded \\
\hline emerged & contrived & & sampled & \\
\hline surfaced & investigated & & randomized & \\
\hline \multirow[t]{6}{*}{ appeared } & obtained & & extended & \\
\hline & connected & & used & \\
\hline & applied & & utilized & \\
\hline & built & & employed & \\
\hline & sought & & expanded & \\
\hline & examined & & & \\
\hline
\end{tabular}

Note. The list of verbs in this table is by no means exhaustive.

Adapted from "Editorial: A typology of verbs for scholarly writing," by Frels, R. K., Onwuegbuzie, A. J., \& Slate, J. R. (2010b). Research in the Schools, 17(1), p. xxvii. Copyright 2010 by the Mid-South Educational Research Association. 
In contrast, if the author had avoided using the colloquial phrase, "The researcher ran the analysis," and, instead, had used the phrase "The researcher conducted the analysis," a first round of back translation would have yielded the same meaning. Indeed, the Spanish translation of the phrase "The researcher conducted the analysis" is as follows:

El investigador realizó el análisis

And when this Spanish translation is translated back to English, it yields the following phrase:

The researcher conducted the analysis.

This single back-translated phrase is identical to the original phrase. This example demonstrates the (potential) negative consequences of using colloquial words/phrases, especially for readers whose first language is not English. And one can assume that this rule regarding the avoidance of colloquial words/phrases is applicable to scholarly works written in any language!

\subsubsection{Split Infinitives}

Figure 1 reveals that the prevalence of the use of colloquial words/phrases $(76.1 \%)$ is followed very closely by the use of split infinitives (i.e., 75.9\%). According to Dictionary.com, a split infinitive is "an expression in which there is a word or phrase, especially an adverb or adverbial phrase, between to and its accompanying verb form in an infinitive, as in to readily understand" (http://www.dictionary.com/browse/split-infinitive?s=t) [emphasis in original]. However, it should be noted that the prescriptive rule against using split infinitives has been the subject of debate since its use was first criticized by an Anonymous author from North America in 1834, as follows:

The practice of separating the prefix of the infinitive mode from the verb, by the intervention of an adverb, is not unfrequent among uneducated persons ... I am not conscious, that any rule has been heretofore given in relation to this point ... The practice, however, of not separating the particle from its verb, is so general and uniform among good authors, and the exceptions are so rare, that the rule which I am about to propose will, I believe, prove to be as accurate as most rules, and may be found beneficial to inexperienced writers. It is this:- The particle, TO, which comes before the verb in the infinitive mode, must not be separated from it by the intervention of an adverb or any other word or phrase; but the adverb should immediately precede the particle, or immediately follow the verb. ("Inaccuracies of diction. Grammar," 1834, p. 469)

However, objection to the use of split infinitives only became popularized after Henry Alford - a English churchman, theologian, textual critic, scholar, artist, poet, hymnodist, and writer-formally issued his criticism in his famous 1864 publication, as follows:

A correspondent states as his own usage, and defends, the insertion of an adverb between the sign of the infinitive mood and the verb. He gives as an instance, "to scientifically illustrate". But surely this is a practice entirely unknown to English speakers and writers. It seems to me, that we ever regard the to of the infinitive as inseparable from its verb. 
And, when we have already a choice between two forms of expression, "scientifically to illustrate" and "to illustrate scientifically," there seems no good reason for flying in the face of common usage. (Alford, 1864, p. 188)

Such criticisms continued into the 20th century and through the 1960s. However, such criticisms of the use of split infinitives (i.e., non-splitters) were met with opposition (i.e., splitters) by equally prominent authors. For example, George Bernard Shaw-an Irish playwright, critic, and polemicist - wrote letters to newspapers providing support to writers who used split infinitives. The 1960s and beyond have seen more of an acceptance of the use of split infinitives. Notwithstanding, some teachers of English at both the secondary and tertiary levels still caution students against using split infinitives in their formal writings, contending that (a) the "to" of the infinitive is inseparable from the corresponding verb, and (b) in classical languages like Latin and Greek, the infinitive is a single word that is impossible to split.

The prevailing view is that the split infinitive does not represent a (serious) grammatical error. Nevertheless, I suggest that authors at least consider avoiding the use of splitting infinitives in scholarly works unless the alternative wording is awkward or would change the meaning of the sentence, if for no other reason than one or more of the reviewers of their manuscripts might interpret the split infinitive as representing a grammatical error, which, in turn, might adversely affect their overall assessment of the manuscript. My recommendation here is consistent, for example, with that of the Columbia Guide, wherein writers are encouraged to "follow the conservative path [of not using split infinitives when they are unnecessary], especially when you're uncertain of your readers' expectations and sensitivities in this matter" (Wilson, 1993, p. 411).

The authors of APA (2010) do not provide any discussion of the split infinitive. However, bearing in mind the controversy surrounding it, this is not surprising. Thus, despite the current findings, I suggest that the next edition of the APA Publication Manual also not include any discussion. This way, authors can decide for themselves whether or not to use split infinitives.

\subsubsection{Subject-Verb Disagreement}

Although, at least to some extent, the two most common formal grammatical errors identified in this study are subject to debate among writers - especially between strict grammarians and their counterparts - the third most common formal grammatical error, namely, subject-verb disagreement, is, for the most part, not open to debate because, with a few exceptions (e.g., the unresolved debate between the phrases "one or more ... is" and "one or more ... are" [i.e., whether one should use singular or plural with "one or more"]), the grammatical rules associated with this violation are very explicit and uncontroversial. Thus, it is disturbing that such a high proportion of RITS authors - nearly one half $(45.7 \%)$ - made one or more errors of this type. Specifically, subject-verb disagreement refers to the fact that the subject and verb in a sentence are not consistent in number. That is, these two elements are neither both singular nor both plural. The authors of APA address this form of grammatical error: 
A verb must agree in number (i.e., singular or plural) with its subject, regardless of intervening phrases that begin with such words as together with, including, plus, and as well as.

\section{Correct:}

The percentage of correct responses as well as the speed of the responses increases with practice.

Incorrect:

The percentage of correct responses as well as the speed of the responses increase with practice.

The plural form of some nouns of foreign origin, particularly those that end in the letter a, may appear to be singular and can cause authors to select a verb that does not agree in number with the noun.

Correct:

The data indicate that Terrence was correct.

\section{Incorrect:}

The data indicates that Terrence was correct.

\section{Correct:}

The phenomena occur every 100 years.

\section{Incorrect:}

The phenomena occurs every 100 years.

Consult a dictionary (APA prefers Merriam-Webster's Collegiate Dictionary, 2005) when in doubt about the plural form of nouns of foreign origin. For examples of agreement of subject and verb with collective nouns, see the APA Style website (www.apastyle.org). (APA, 2010, pp. 78-79)

For authors who commit subject-verb disagreement errors, here are some quizzes/exercises that that they might find useful in helping them eliminate these errors in the future:

http://www.englishpractice.com/quiz/subjectverb-agreement-exercise

http://www.chompchomp.com/hotpotatoes/sva01.htm

http://www.englishexercises.org/makeagame/viewgame.asp?id=2543

https://www.wisc-online.com/learn/humanities/linguistics/wcn3302/subject---verb-agreement --exercise-1

http://languagearts.pppst.com/subject-verb-agreement.html

Authors also might consider installing an English language writing-enhancement platform 
such as Grammarly (circa 2009), which is both a proofreading (i.e., grammar checker and spell checker) and plagiarism-detection resource that checks more than 250 grammar rules (https://www.grammarly.com/).

\subsubsection{Mismatch between Possessive Pronoun and Noun}

The fourth most common formal grammatical error was mismatch between possessive pronoun and noun, committed by $43.1 \%$ of RITS authors. Strictly speaking, a possessive pronoun is a pronoun that can replace a noun phrase to indicate ownership (e.g., "This manuscript is mine"). There are two broad categories of possessive pronouns: weak possessive pronouns and strong possessive pronouns. Weak possessive pronouns (also called possessive determiners) serve as determiners in front of nouns (e.g., "My manuscript has been accepted for publication"). The weak possessive pronouns are my, your, her, his, its, our, and their. In contrast, strong possessive pronouns (also called absolute possessive pronouns) stand alone, and thus are a type of independent genitive. The strong possessive pronouns are mine, yours, his, hers, its, ours, and theirs. A mismatch between possessive pronoun and noun refers to the use of weak possessive pronouns, especially with respect to the use of the possessive pronoun their. An example of a mismatch would be when an author incorrectly uses the phrase "Authors should avoid making grammatical errors in their manuscript" [emphasis added]. And because in this context, the word "their" represents a possessive pronoun in plural form, the plural form of manuscript should be used such that the phrase reads as follows: "Authors should avoid making grammatical errors in their manuscripts" [emphasis added].

Although the APA Publication Manual contains a whole section on pronouns (i.e., Section 3.20, pp. 79-80; Section 3.22, pp. 83-84), no mention is made of the grammatical error pertaining to the mismatch between possessive pronoun and noun. Thus, based on the present findings, I suggest that discussion of this error be included in the next edition of the APA Publication Manual. In particular, this discussion can be appended to the section entitled "Pronouns" (i.e., Section 3.20).

\subsubsection{Use of may Instead of Might}

The fifth most common formal grammatical error is the use of may instead of might. The words may and might are called modal auxiliary verbs (i.e., modal auxiliaries), which are "helping verbs" that function differently from most other verbs. They do not denote an action, but rather express an attitude toward an action that often is represented by an infinitive. A significant proportion of authors - including one third of RITS authors - use the auxiliary verbs may and might as if they are strictly interchangeable. However, this is not the case. Indeed, when used in the context of granting or seeking permission, might represents the past tense of may. Moreover, might is considerably more tentative than is may, as follows:

- May I co-author this manuscript with you?

- If you end up deciding to write a manuscript about grammatical errors, might I co-author this manuscript with you? 


\section{Macrothink}

In the context of communicating possibility, may and might are interchangeable present and future forms, respectively. Further, the format might + have + past participle represents the past form.

For some authors, a common confusion surrounds the sense of possibility in may versus the implication of might, which distinguishes whether a hypothetical situation has or has not occurred. For example, let us suppose that an author has submitted a manuscript to a journal for review for possible publication. Let us suppose further that the author receives an email from the editor with the words "Decision on your manuscript" on the subject line. Now, prior to the author opening the email and reading it, the author could state that the manuscript "may have been rejected." After reading the email and finding out that the manuscript was accepted, the author can now state that the manuscript "might have been rejected" because it represents a hypothetical situation that has not occurred. Finally, I suggest that authors utilize the following general rule of thumb:

- may is used to denote permission

- $\quad$ might is used to denote possibility

- $\quad$ can is used to denote ability

Interestingly, no mention is made of the may versus might grammatical error by the authors of APA (2010). Thus, based on the present findings, I suggest that discussion of this error be included in the next edition of the APA Publication Manual.

\subsubsection{Use of between Instead of among}

The sixth most common formal grammatical error surrounds the use of between instead of among, committed by approximately one fourth of RITS authors. This error occurs if between is used when more than two elements are involved. Instead, between only should be used when exactly two elements are involved, whereas among should be used when more than two elements are involved. I refer authors to the following websites:

http://www.editingandwritingservices.com/AmongBetween.html

http://www.ehow.com/how_2104845_use-among-between-correctly.html

http://languagerules.wordpress.com/2006/09/07/between-vs-among/

http://wiki.answers.com/Q/When_would_one_use_among_vs_between_in_the_English_lang uage

Interestingly, no mention is made of the between versus among grammatical error by the authors of APA (2010). Thus, based on the present findings, I suggest that discussion of this error be included in the next edition of the APA Publication Manual.

\subsubsection{Paragraphs Containing Less Than Three Sentences}

The seventh most common formal grammatical error is the construction of paragraphs with less than three sentences, committed by approximately one fourth of RITS authors. However, 
paragraphs with less than three sentences tend to end abruptly. Indeed, ideally, at a minimum, a paragraph should contain (a) a beginning sentence, (b) at least one sentence for the body of a paragraph, and (c) a concluding statement. Consistent with my assertion here, Onwuegbuzie et al. (2013) documented that the mean number of sentences per paragraph of 63 manuscripts submitted to a journal over a 3 -year period was $5.42(S D=5.60)$. The authors of APA (2010) state the following regarding paragraphs:

Similar cautions apply to paragraph length. Single-sentence paragraphs are abrupt. Paragraphs that are too long are likely to lose the reader's attention. A new paragraph provides a pause for the reader-a chance to assimilate one step in the conceptual development before beginning another. If a paragraph runs longer than one double-spaced manuscript page, you may lose your readers. Look for a logical place to break a long paragraph, or reorganize the material. (p. 68)

Interestingly, it can be seen from this paragraph that the authors of APA (2010) criticize the use of single-sentence paragraphs but not the use of two-sentence paragraphs. Thus, based on the present findings, I suggest that discussion of the problems associated with using two-sentence paragraphs be included in the next edition of the APA Publication Manual.

\subsubsection{Adverb Used to Begin Sentence without a Comma}

The eighth most common formal grammatical error is using adverbs without a comma to begin a sentence. This error was committed by approximately one fourth of RITS authors. I refer authors to the following websites:

https://www.ego4u.com/en/cram-up/writing/comma?07

http://theeditorsblog.net/2016/02/21/a-tale-of-adverbs-and-the-comma/

http://www.aje.com/en/arc/editing-tip-commas-conjunctive-adverbs/

https://writing.wisc.edu/Handbook/ConjAdv.html

The authors of APA (2010) discuss the use of adverbs as follows:

Adverbs: Adverbs can be used as introductory or transitional words. Adverbs modify verbs, adjectives, and other adverbs and express manner or quality. Some adverbs, however-such as fortunately, similarly, certainly, consequently, conversely, and regrettably can also be used as introductory or transitional words as long as the sense is confined to, for example, "it is fortunate that" or "in a similar manner." Use adverbs judiciously as introductory or transitional words. Ask yourself whether the introduction or transition is needed and whether the adverb is being used correctly.

Some of the more common introductory adverbial phrases are importantly, more importantly, interestingly, and firstly. Although importantly is used widely, whether its adverbial usage is proper is debatable. Both importantly and interestingly can often be recast to enhance the message of a sentence or simply be omitted without a loss of meaning. 
Correct:

More important, the total amount of available long-term memory activation, and not the rate of spreading activation, drives the rate and probability of retrieval.

Correct:

Expressive behavior and autonomic nervous system activity also have figured importantly ...

Incorrect:

More importantly, the total amount of available long-term memory activation, and not the rate of spreading activation, drives the rate and probability of retrieval.

\section{Correct:}

We were surprised to learn that the total.

We find it interesting that the total.

An interesting finding was that.

Incorrect:

Interestingly, the total amount of available long-term memory activation, and not the rate of spreading activation, drives the rate and probability of retrieval.

\section{Correct:}

First, we hypothesized that the quality of the therapeutic alliance would be rated higher.

Incorrect:

Firstly, we hypothesized that the quality of the therapeutic alliance would be rated higher.

Another adverb often misused as an introductory or transitional word is hopefully. Hopefully means "in a hopeful manner" or "full of hope"; hopefully should not be used to mean "I hope" or "it is hoped."

\section{Correct:}

I hope this is not the case.

Incorrect:

Hopefully, this is not the case. (pp. 82-83) [emphasis in original]

Interestingly, the authors of the APA Publication Manual do not mention explicitly the rule that, with a few exceptions, sentences or clauses beginning with an adverb should be followed by a comma. However, as can be seen, in all the sentences that they provide under 
"Correct" that begin with an adverb, a comma always directly follows this adverb. However, I recommend that explicit discussion of the role of commas when using adverbs be included in the next edition of the APA Publication Manual.

\subsubsection{Use of Contractions}

The ninth most common formal grammatical error is using contractions. This error was committed by approximately one fifth of RITS authors. In the context of manuscripts, a contraction is an abbreviated (i.e., shortened) version of the written forms of a word, syllable, or word group, which are created by omitting internal letters and sounds. Examples of 51 common contractions, presented in alphabetical order, are as follows:

aren't, can't, couldn't, didn't, doesn't, don't, hadn't, hasn't, haven't, he'd, he'll, he 's, I'd, I'll, I'm, I've, isn't, it's, let's, mustn't, shan't, she'd, she 'll, she 's, shouldn't, that's, there's, they'd, they'll, they're, they've, we'd, we're, we've, weren't, what'll, what're, what's, what've, where's, who'd, who'll, who're, who's, who've, won't, wouldn't, you'd, you'll, you're, you've

Contractions typically are appropriate in informal writing. However, in more formal written works, avoiding contractions is a way of establishing a more scholarly tone. Interestingly, no mention is made of the use of contractions by the authors of APA (2010). Thus, based on the present findings, I suggest that discussion of this formal grammatical error be included in the next edition of the APA Publication Manual. I refer authors to the following website:

http://www.grammar-monster.com/glossary/contractions.htm

\subsubsection{Misspelled Words}

The tenth most common formal grammatical error represents misspelled words. According to the authors of APA (2010),

Spelling should conform to standard American English as exemplified in Merriam-Webster's Collegiate Dictionary (2005), the standard spelling reference for APA journals and books; spelling of psychological terms should conform to the APA Dictionary of Psychology (VandenBos, 2007). If a word is not in Webster's Collegiate, consult the more comprehensive Webster's Third New International Dictionary (2002). If the dictionary gives a choice, use the first spelling listed; for example, use aging and canceled rather than ageing and cancelled. (p. 96)

Because English was influenced by several different language families over the course of four periods - namely, Old English (or Anglo-Saxon; circa 450-1100 AD), Middle English (circa 1110-1500 AD), early Modern English (circa 1500-1800 AD), and late Modern English (circa 1800-present) period - and because, even today, new words from other languages are incorporated so easily, in the English language, there are different ways to spell words with the same sound (i.e., homonyms; e.g., their vs. there vs. they're; here vs. hear; bow vs. bough; formally vs. formerly) and different ways to pronounce words with the same spelling (i.e., heteronyms; e.g., To contest the issue the judge held a contest; When I graduate, I will become a graduate; You can insult someone by shouting an insult; The security guard will 
permit you to pass if you show a valid permit; A rebel is someone who has decided to rebel). As such, English spelling is particularly difficult to master even for native speakers. Thus, perhaps it should not be surprising that nearly one fifth of RITS authors commit one or more spelling errors. However, what is surprising is that not all authors use spell check functions just prior to submitting their manuscripts to a journal for possible publication. If they did, they would catch most, if not all, of the spelling errors, as well as other types of errors such as citation errors (Onwuegbuzie, Frels, et al., 2010). As declared by the authors of APA (2010),

Spelling check: Most word-processing programs have a function that checks spelling. Use it. Although an electronic spelling check cannot take the place of proofreading the article, because words spelled correctly may be used incorrectly, it will lessen the chance that typographical errors in the manuscript will make their way into print when your electronic file is used to publish the article. (p. 230) [emphasis in original]

However, authors should not rely solely on electronic spelling check functions to eliminate all their spelling errors because these tools are not 100\% reliable. Specifically, electronic spelling check functions will catch any combinations of letters that do not form a known English word; however, they will miss many incorrectly spelled words that actually form another English word (i.e., homonyms). Thus, instead, authors should be proactive in minimizing spelling errors prior to using the spelling check function. Strategies that I recommend for facilitating proactiveness include the following:

- $\quad$ using a good dictionary such as Merriam-Webster's Collegiate Dictionary, as recommended by the authors of APA (2010)

- checking potentially problematic suffixes in the selected dictionary

○ (e.g., -ance vs. -ence [e.g., acceptance vs. occurrence]; -ant vs. -ent [e.g., blatant vs. apparent]; -cial vs. -tial [e.g., vs. facial vs. partial]; -ible vs. -able [e.g., responsible vs. dependable]; -ibly vs. ably [e.g., responsibly vs. dependably]; -ibility vs. -ability [e.g., responsibility vs. dependability])

- learning the standard pronunciations for frequently misspelled words

- e.g., would have (correct) vs. would of (incorrect)

- $\quad$ paying attention to homophones (i.e., words pronounced the same as another but that differ in meaning, whether spelled the same way or not) and near-homophones

$\circ$ heir vs. air

$\circ \quad$ except vs. accept

- discreet vs. discrete

$\circ \quad$ affect vs. effect

○ compliment vs. complement

$\circ \quad$ desert vs. dessert 
$\circ \quad$ its vs. it's

- led vs. lead

- lose vs. loose

- principle vs. principal

- stationary vs. stationery

$\circ \quad$ their vs. there

○ whose vs. who's

- your vs. you're

- becoming familiar with English spelling rules, such as the following:

○ $\quad i$ before $e$ except after $c$ (e.g., believe, receive), or when sounded like "ay" (e.g., neighbor, weigh)

○ when adding suffixes to words ending in $y$, change the $y$ to an $i$ (e.g., happy $\rightarrow$ happier, bounty $\rightarrow$ bountiful)

- when adding suffixes to words ending in $y$, the $y$ is retained when the suffix itself begins with an $i$ (e.g., marry $\rightarrow$ marrying, baby $\rightarrow$ babyish)

- when adding suffixes that begin with a vowel (e.g., -able, -ible, -ous) to words ending in silent $e$, drop the final $e(e . g$., desire $\rightarrow$ desirable, response $\rightarrow$ responsible, $\arg u e \rightarrow \arg$ uing)

- creating a list of difficult-to-spell words that is updated regularly, and keeping the list on or near the computer while writing.

Becoming adept at spelling initially can be very time-consuming. However, if authors do not rely on spell checking functions but rather look up words that they are unsure how to spell, they will become actively engaged in the process of spelling. The good news is that as one becomes familiar with spelling rules, increasingly less time is needed to consult these authoritative sources.

\subsubsection{Incorrect Use of Possessive Nouns}

The 11th most common formal grammatical error-representing the final formal grammatical error with a large effect size - is the incorrect use of possessive nouns. This error was committed by approximately one sixth of RITS authors. The possessive case is predominantly used for indicating possession (i.e., ownership). Specifically, the possessive case applies to nouns, pronouns, and adjectives. With nouns, which is when the error mostly occurs, the possessive case usually is shown by preceding it with of or by adding 's (or just ') to the end of the word. Unfortunately, some authors misapply these apostrophes. In particular, these authors violate one or more of the following rules regarding apostrophe usage: 
- For singular nouns (e.g., editor), the apostrophe should appear before the $s$ (e.g., the editor's decision)

- $\quad$ For plural nouns (e.g., editors), the apostrophe should appear after the s (e.g., the editors' decision)

- For singular nouns ending in -s (e.g., Chris), an apostrophe followed by $s$ should appear after the noun (e.g., Chris's decision)

- For plural nouns not ending in -s (e.g., people), an apostrophe followed by $s$ should appear after the noun (e.g., People's rights)

The authors of APA (2010) state the following:

In general, the possessive of a singular name is formed by adding an apostrophe and an $\mathrm{s}$, even when a name ends in $\mathrm{s}$; the possessive of a plural name is formed by adding an apostrophe. A list of examples follows as well as some exceptions.

\section{Singular Plural}

Freud's the Freuds'

James's the Jameses'

Watson's the Watsons'

Skinner's the Skinners'

Exceptions: Use an apostrophe only with the singular form of names ending in unpronounced s (e.g., Descartes'). It is preferable to include of when referring to the plural form of names ending in unpronounced s (e.g., the home of the Descartes). (pp. 96-97)

I refer readers to the following link:

http://www.grammar-monster.com/glossary/possessive_case.htm

As noted previously, the incorrect use of possessive nouns marks the last of the 11 formal grammatical errors whose prevalence rate represented a large effect size.

\subsubsection{Overall Frequency of Formal Grammatical Errors}

For each of the 117 manuscripts, the total number of unique grammatical errors was computed. The total number of grammatical errors ranged from 0 to 11 , with a mean of 5.05 $(S D=2.19)$. Interestingly, the following list presents the approximate percentages of manuscripts that contain the least number of grammatical errors:

- $\quad 1.7 \%$ of manuscripts contained no errors

- $\quad 4.3 \%$ of manuscripts contained 1 or less different errors

- $\quad 9.6 \%$ of manuscripts contained 2 or less different errors 
- $22.6 \%$ of manuscripts contained 3 or less different errors

- $\quad 45.2 \%$ of manuscripts contained 4 or less different errors

- $\quad 58.3 \%$ of manuscripts contained 5 or less different errors

- $77.4 \%$ of manuscripts contained 6 or less different errors

- $\quad 88.7 \%$ of manuscripts contained 7 or less different errors

- $\quad 91.3 \%$ of manuscripts contained 8 or less different errors

- $\quad 97.4 \%$ of manuscripts contained 9 or less different errors

- $\quad 98.3 \%$ of manuscripts contained 10 or less different errors

Although it is reasonable for an author to commit one or two different grammatical errors, it has been my experience that committing much more than this number becomes distracting for the reviewer. Thus, it is surprising that more than one half of RITS manuscripts $(54.8 \%)$ contain five or more different grammatical errors. And when one or more of these errors are repeated in a manuscript - as is often the case - the total number of grammatical errors could be extremely large, thereby adversely affecting both the clarity and quality of the manuscript.

3.2 Research Question 2: What Is the Relationship between the Overall Frequency of Formal Grammatical Errors and Style Guide Errors (i.e., APA Errors) among Manuscripts Submitted to a Journal?

According to Onwuegbuzie and Daniel (2002), a standardized skewness coefficient (i.e., skewness coefficient divided by its standard error) or a standardized kurtosis coefficient (i.e., kurtosis coefficient divided by its standard error) that lies outside the \pm 3 range indicates serious departures from normality. Interestingly, no evidence of non-normality merged because both the standardized skewness coefficient (1.41) and standardized kurtosis coefficient (0.43) were within the bounds of normality. Thus, the use of parametric inferential statistical procedures was justified.

A series of Pearson $r \mathrm{~s}$ was used to determine the relationship between the total number of different grammatical errors and the number of APA errors. After applying the Bonferroni adjustment to control for the inflation of Type 1 error (cf. Chandler, 1995; Ho, 2006; Manly, 2004; Vogt, 2005), the total number of different grammatical errors was statistically significantly and moderately related to both the number of APA errors $(r=.30, p<.025)$ and the number of APA error themes ${ }^{1}(r=.41, p<.025)$. These correlations indicate that authors who tended to make many different grammatical errors also tended to be those who make many APA errors. This suggests that the lack of attention that some of the authors show to grammatical rules is the same lack of attention that they demonstrate towards complying to the APA style guide.

3.3 Research Question 3: What Is the Relationship between the Overall Frequency of Formal Grammatical Errors and Citation Errors among Manuscripts Submitted to a Journal?

The relationship between the total number of different grammatical errors and the total 
number of citation errors was not statistically significant, $r=.18, p>.05$. This finding suggests that authors who write manuscripts that contain many different grammatical errors are not necessarily those authors who commit the most common APA error, namely, the citation error (Onwuegbuzie, Combs, et al., 2011; Onwuegbuzie, Frels, et al., 2010). In other words, committing grammatical errors represents a distinct construct from committing citation errors.

\subsection{Research Question 4: What Is the Relationship between the Overall Frequency of Formal Grammatical Errors and Select Demographic Characteristics (e.g., Number of Authors, Gender of the Lead Author, Length of Manuscript, Genre of Manuscript) among Manuscripts Submitted to a Journal?}

After applying the Bonferroni adjustment to control for the inflation of Type I error (i.e., adjusted $\alpha=.05 / 7=.0071)$, a series of Pearson $r$ s revealed no statistically significant relationship (i.e., $p>.0071$ ) between the total number of different grammatical errors and the following variables: (a) number of paragraphs in the manuscript, $r=.01$; (b) number of co-authors: $r=.11$; and (c) the gender of lead author, $r=.12$. However, a statistically significant relationship (i.e., $p<.0071$ ) emerged between the total number of different grammatical errors and the following variables: $(d)$ number of characters in the manuscript, $r$ $=.38$; (e) number of words in the manuscript, $r=.33$; (f) number of sentences in the manuscript, $r=.33$; and (g) number of pages in the manuscript, $r=.35$. Using Cohen's (1988) criteria, these four statistically significant relationships represented large effect sizes. This set of correlations indicated that manuscripts that contained the largest number of different grammatical errors tended to contain the most characters, words, sentences, and pages. These findings have intuitive appeal because it suggests that authors of longer manuscripts should exercise even more meticulousness when checking their manuscripts for grammatical errors than should authors of shorter manuscripts.

It could be argued that the statistically non-significant relationship between the total number of different grammatical errors and the number of co-authors is not a positive finding because it might suggest a bystander effect (Darley \& Latané, 1968; Hudson \& Bruckman, 2004; Levine \& Thompson, 2004), wherein the presence of multiple co-authors encourages inaction in checking carefully for grammatical errors. Interestingly, Onwuegbuzie, Frels, et al. (2010) surmised that a bystander effect prevails with regard to citation errors, wherein manuscripts written by larger authorship teams contained more citation errors. According to Onwuegbuzie, Frels, et al. (2010), the inaction reflecting a bystander effect might stem from (a) pluralistic ignorance (i.e., failure of other co-authors to identify grammatical errors signals to that co-author that such a check is not needed); (b) a diffusion of responsibility (i.e., all co-authors assume that one or more of the other co-authors will check for grammatical errors such that each co-author believes he/she is less responsible for conducting this check and so does not do so); (c) imposter threat (Harvey \& Katz, 1985) wherein each co-author believes that one or more of the other co-authors are more qualified to conduct the grammar checks and, therefore, her/his assistance is not necessary, and might even reveal her/his own incompetence; or (d) a lack of leadership wherein the leader of the manuscript - typically the lead author-does not clearly define the roles and responsibilities of each author. Whichever factor might be 
responsible, it is likely that greater communication among co-authors would lead to larger authorship teams taking advantage of their collaborative teams to check their manuscripts more carefully for grammatical errors.

Further, a comparison of the total number of different grammatical errors contained in quantitative, qualitative, and mixed research manuscripts identified an intuitive ordering, with quantitative research manuscripts $(M=4.46, S D=2.09)$ and qualitative research manuscripts $(M=6.00, S D=2.42)$ residing at opposite ends of the spectrum, and with mixed research manuscripts $(M=4.96, S D=1.89)$ residing in between these two genres. More specifically, an analysis of variance (ANOVA) revealed a statistically significant difference in the total number of different grammatical errors among the quantitative, qualitative, and mixed research manuscripts, $F(2,115)=4.70, p=.011$. A Scheffé post-hoc test revealed no statistically significant difference in the total number of different grammatical errors between the mixed research manuscripts and both the qualitative research manuscripts and the quantitative research manuscripts. However, the qualitative research manuscripts contained statistically significantly more different grammatical errors than did the quantitative research manuscripts. Cohen's (1988) $d$ effect size associated with this difference between the qualitative and quantitative research manuscripts was moderate-to-large at 0.69. Although this finding might be surprising, upon deeper reflection, it seems quite intuitive. Specifically, qualitative research is primarily narrative and, consequently, qualitative reports are more verbose than are quantitative reports. Thus, it is likely that this relatively greater verboseness has the potential to increase the incidence of grammatical errors. In order to explore more closely the nature of the difference in prevalence of grammatical errors between quantitative and qualitative research manuscripts, these two genres of manuscripts were compared via odds ratios with respect to each of the 35 most common formal grammatical errors.

Of these 35 errors, five of them practically significantly discriminated the two genres. Specifically, compared to quantitative research manuscripts, qualitative research manuscripts were (a) 3.06 times $(95 \% \mathrm{CI}=1.01,10.34)$ more likely to contain colloquial words/phrases, (b) 5.50 times $(95 \% \mathrm{CI}=1.54,19.67)$ more likely to contain contractions, (c) 4.71 times $(95 \% \mathrm{CI}=1.30,17.08)$ more likely to contain unparallel construction (i.e., incorrect placement in a sentence of the terms "not only" and/or "but also"; non-pairing of "either" with "or"; non-paring of "neither" with "nor"), (d) 4.77 times $(95 \% \mathrm{CI}=1.13,20.25)$ more likely to contain sentences that end with a preposition, and (e) 3.06 times (95\% CI $=1.09$, 8.61) more likely to contain paragraphs with less than three sentences. The first four grammatical errors might reflect the relatively more conversational and casual styles of writing used by some authors of qualitative research manuscripts, which lend themselves more to grammatical errors. In contrast, the more frequent use of paragraphs with less than three sentences used by some authors of qualitative research manuscripts might reflect their use of short paragraphs to introduce quotations that represent the voices of their participants. In any case, I suggest that before they submit their works to a journal for review for possible publication, authors of qualitative manuscripts examine qualitative research articles that were previously published in that journal to determine the extent to which these five sets of grammatical errors appear in them, thereby establishing how tolerant the editor of that journal 
is with regard to these grammatical errors.

\subsection{Research Question 5: What Is the Relationship between the Overall Frequency of Formal Grammatical Errors and Manuscript Disposition among Manuscripts Submitted to a Journal?}

An ANOVA revealed a statistically significant difference in the total number of different grammatical errors as a function of manuscript disposition, $F(2,115)=3.16, p<.05$. A Scheffé post-hoc test revealed that manuscripts that were accepted for publication $(M=3.29$, $S D=1.25$ ) had a statistically significantly smaller number of different grammatical errors than did both manuscripts that were rejected $(M=4.46, S D=1.91)$ and manuscripts that received a revise-and-resubmit decision $(M=5.26, S D=2.18)$. Cohen's (1988) $d$ effect size associated with these differences were 0.64 and 0.97 , respectively. However, no statistically significant difference in the total number of different grammatical errors emerged between manuscripts that were rejected and manuscripts that received a revise-and-resubmit decision. A somewhat surprising finding was that, although not representing a statistically significant difference, manuscripts that received a revise-and-resubmit decision contained a larger number of different grammatical errors than did manuscripts that were rejected. However, on reflection, this finding suggests that even though these former manuscripts contained an unacceptably large number of different grammatical errors, the content of these manuscripts must have been sufficiently appealing - at least relative to their counterparts that were rejected - to warrant an opportunity for the authors to revise them. Of course, because these findings are correlational, follow-up studies are needed, optimally using mixed research techniques (see, for e.g., Johnson \& Onwuegbuzie, 2004; Johnson, Onwuegbuzie, \& Turner, 2007; Tashakkori \& Teddlie, 2010), to explore the causal nature of this relationship between the prevalence of grammatical errors and quality of manuscript. Notwithstanding, based on the hundreds of reviewer comments that I have read during my 20 years of experience as an editor of three journals, guest editor of numerous special issues for various journals, and reviewer for and editorial board member of numerous journals, I have observed repeatedly that when a manuscript contains minimal or no grammatical errors, it is well received by the reviewers. Contrastingly, numerous grammatical errors reduce the coherence of a manuscript, which, in turn, make it more difficult for journal reviewers to follow the author's logic of argumentation.

\subsection{Research Question 6: Which Grammatical Errors, If Any, Discriminate Manuscripts that} are Rejected and Manuscripts that Are Not Rejected?

A series of All Possible Subsets (APS) canonical discriminant analysis procedures was conducted to determine which of the 11 most common formal grammatical errors (i.e., formal grammatical errors with prevalence rates with a large effect size) best predicted whether the editor's decision for a manuscript was reject versus non-reject (i.e., revise and resubmit or accept). Each of the 11 formal grammatical variables served as a predictor variable in separate analyses, with the editor's decision serving as the dependent variable in the analyses. All possible models involving some or all of the 11 formal grammatical variables were examined. Indeed, in APS discriminant analyses, separate discriminant functions are 
computed for all thematic variables singly, all possible pairs of thematic variables, all possible trios of thematic variables, and so forth, until the best subset of thematic variables is identified according to some pre-specified criteria. For this study, the criteria used were Wilks' lambda, the probability level (i.e. $p$ value), the canonical correlation coefficient, the standardized canonical discriminant function coefficients, the structure coefficients, and the odds ratio (primary effect size measure). It should be noted that the APS discriminant analysis is different from stepwise discriminant analysis, in which the order of entry of variables is based solely on the probability level. In fact, stepwise discriminant analysis does not guarantee the optimal model, and thus many researchers criticize this type of analysis, instead advocating some form of canonical discriminant analysis (Onwuegbuzie \& Daniel 2003).

The selected model indicated that the following three formal grammatical variables contributed statistically significantly to the prediction of the editor's decision: use of contractions, use of "may" instead of "might," and adverbs used to begin a sentence without a comma. The canonical discriminant analysis revealed a statistically significant canonical function $\left(\times^{2}[3]=13.76, p<.001\right.$; Wilks's Lambda $\left.=0.83\right)$. The corresponding canonical correlation was .42 , which suggested a medium-to-large effect size (Cohen, 1988). In addition, the group centroid (the average score on the discriminant function for manuscripts in both groups) for this function was -.41 for manuscripts that were rejected and .50 for manuscripts that were not rejected. These statistics indicated that the discriminant function maximally separated manuscripts that were rejected from manuscripts that were not rejected.

An examination of the standardized canonical discriminant function coefficient (Table 2) revealed that, using a cutoff loading of 0.3 (Lambert \& Durand, 1975; Tabachnick \& Fidell, 2007), all three formal grammatical errors were practically significant. Further, the structure coefficients (i.e., structure matrix) between the independent variable set and the standardized canonical discriminant function (Table 2) indicated that, using a cutoff loading of 0.3 (Lambert \& Durand, 1975; Tabachnick \& Fidell, 2007), all three formal grammatical errors discriminated manuscripts that were rejected and manuscripts that were not rejected. For both the standardized canonical discriminant function coefficient and the structure matrix, use of contractions was the most significant predictor of manuscript disposition. This formal grammatical error was followed in importance by "may" instead of "might". The variables with a negative coefficient (i.e., all three variables) suggest that manuscripts that contained these formal grammatical errors were more likely to be rejected. Thus, the presence of one or more of the three formal grammatical errors (i.e., use of contractions, use of "may" instead of "might", and adverbs used to begin a sentence without a comma) were predictive of the manuscript being rejected. Specifically, manuscripts that contained one or more incidences of contractions were $1.28(95 \% \mathrm{CI}=1.09,1.51)$ times more likely to be rejected, manuscripts that contained one or more incidences of the use of "may" instead of "might" were 2.14 (95\% $\mathrm{CI}=1.09,4.23)$ times more likely to be rejected, and manuscripts that contained one or more incidences of adverbs used to begin a sentence without a comma were $1.90(95 \% \mathrm{CI}=1.01$, 4.35) times more likely to be rejected. 
Table 2. Standardized and structure coefficients for selected readability variables

\begin{tabular}{|l|l|l|}
\hline Variable & Standardized Coefficient & Structure Coefficient \\
\hline Use of contractions & $-.75^{*}$ & $-.78^{*}$ \\
\hline Use of "may" instead of "might" & $-.47^{*}$ & $-.60^{*}$ \\
\hline $\begin{array}{l}\text { Adverbs used to begin a sentence } \\
\text { without a comma }\end{array}$ & $-.35^{*}$ & $-.39^{*}$ \\
\hline
\end{tabular}

Note. ${ }^{*}$ coefficients with effect sizes larger than .3 (Lambert \& Durand, 1975).

\section{Conclusions}

The present study is unique in at least four ways. First, it represents the only study formally to examine the prevalence of grammatical errors in scholarly works in general and manuscripts submitted to a journal in particular. Second, this study represents the first work to examine the link between grammatical errors and style guide errors, including citation errors, among manuscripts submitted to a journal. Third, this work represents the first study to investigate the relationship between grammatical errors and select demographic characteristics (i.e., number of authors, genre of manuscript) among manuscripts submitted to a journal. Fourth, and most importantly, this study represents the first attempt to examine the relationship between grammatical errors and manuscript disposition among manuscripts submitted to a journal.

The results from this current study demonstrate several unique findings in relation to grammatical errors and manuscript preparation and submission. In particular, I identified the 35 most common formal grammatical errors committed by RITS authors (Figure 1), with two of them being committed by more than $75 \%$ of RITS authors, four of them being committed by more than $40 \%$ of RITS authors, five of them being committed by more than $33 \%$ of RITS authors, eight of them being committed by more than $25 \%$ of RITS authors, and 11 of them being committed by more than $16 \%$ of RITS authors. However, the most important finding of the present investigation is the link identified between grammatical errors and disposition of manuscripts. Yet, regardless of whether this link is causal in nature, few reviewers and editors would argue that striving to minimize formal grammatical errors in manuscripts is not a worthwhile goal.

Consequently, I recommend that authors consider using Figure 1 as a guide when learning how to write with discipline in general and when preparing their manuscripts in particular. Indeed, I contend that Figure 1 can assist authors - beginning authors, emergent authors, and experienced authors alike - in focusing their efforts on improving their grammar, perhaps in order of the prevalence rates in this table, by ignoring the grammatical errors that they do not make, and focusing on the errors that they themselves are apt to commit. Indeed, after using Figure 1 and Figure 2 to identify their most frequent errors, authors might find it helpful to create a personalized checklist to use when editing their own works. 
In the same vein, I believe that Figure 1 and Figure 2 would serve as useful starting points for those persons who serve as instructors of research methodology courses, instructors of scholarship, mentors, advisors, and thesis/dissertation committee members and chairs/supervisors. Focusing on these most common formal grammatical errors not only provides a much more manageable set of grammatical rules for authors to learn, but likely provides a more efficient method of teaching how to write with discipline. Further, editors also might find the information in Figure 1 and Figure 2 useful. For example, editors can use the errors presented in Figure 1 to develop checklists that are used by their reviewers to assess the quality of manuscripts with respect to writing style. Finally, authors of the APA Publication Manual might use this information to determine which grammatical rules and guidelines to emphasize in future editions.

As stated by the authors of APA (2010), "Incorrect grammar and careless construction of sentences distract the reader, introduce ambiguity, and generally obstruct communication" ( $p$. 77). As such, it is my hope that the findings of this study bring to the fore the importance of paying attention to grammar when preparing manuscripts. It is only by doing so that authors can "write with discipline," as recommended by Onwuegbuzie and Combs (2009, p. 116).

\section{References}

Alford, H. (1864). A plea for the Queen's English: Stray notes on speaking and spelling. Retrieved from https://archive.org/stream/pleaforqueenseng00alfouoft\#page/188/mode/2up

American Psychological Association. (2010). Publication manual of the American Psychological Association (6th ed.). Washington, DC: Author.

Berelson, B. (1952). Content analysis in communicative research. New York, NY: Free Press.

Chandler, C. R. (1995). Practical considerations in the use of simultaneous inference for multiple tests. Animal Behaviour, 49, 524-527. https://doi.org/10.1006/anbe.1995.0069

Cohen, J. (1988). Statistical power analysis for the behavioral sciences (2nd ed.). Hillsdale, NJ: Lawrence Erlbaum.

Constas, M. A. (1992). Qualitative data analysis as a public event: The documentation of category development procedures. American Educational Research Journal, 29, 253-266. https://doi.org/10.3102/00028312029002253

Darley, J. M., \& Latané, B. (1968). Bystander intervention in emergencies: Diffusion of responsibility. Journal of Personality and Social Psychology, 8, 377-383. https://doi.org/10.1037/h0025589

Encyclopaedia Britannica. (n.d.). Punctuation. Retrieved from https://www.britannica.com/ topic/punctuation

Fielding, N. G., \& Lee, R. M. (1998). Computer analysis and qualitative research. Thousand Oaks, CA: Sage.

Frels, R. K., Onwuegbuzie, A. J., \& Slate, J. R. (2010a). Editorial: A step-by-step guide for 
creating tables. Research in the Schools, 17(2), xxxviii-lix. Retrieved from http://msera.org/docs/RITS_17_2_Tables.pdf

Frels, R. K., Onwuegbuzie, A. J., \& Slate, J. R. (2010b). Editorial: A typology of verbs for scholarly writing. Research in the Schools, 17(1), xiv-xxv. Retrieved from http://msera.org/docs/RITS_17_1_Verbs.pdf

Hahs-Vaughn, D. L., Onwuegbuzie, A. J., Slate, J. R., \& Frels, R. K. (2009). Editorial: Bridging research-to-practice: Enhancing knowledge through abstracts. Research in the Schools, 16(2), xxxvii-xlv. Retrieved from http://msera.org/docs/RITS_16_2_Abstracts.pdf

Harvey, J., \& Katz, C. (1985). If I'm so successful, why do I feel like a fake? The imposter phenomenon. New York, NY: St. Martin's.

Ho, R. (2006). Handbook of univariate and multivariate data analysis and interpretation with SPSS. London, England: Chapman \& Hall. https://doi.org/10.1201/9781420011111

Hudson, J. M., \& Bruckman, A. S. (2004). The bystander effect: A lens for understanding patterns of participation. Journal of the Learning Sciences, 13, 165-195. https://doi.org/ $10.1207 / \mathrm{s} 15327809 \mathrm{j} 1 \mathrm{~s} 1302 \_2$

"Inaccuracies of Diction, Grammar". (1834, December). The New-England Magazine, 7(6), 467-470.

Johnson, R. B., \& Onwuegbuzie, A. J. (2004). Mixed methods research: A research paradigm whose time has come. Educational Researcher, 33(7), 14-26. https://doi.org/10.1177/1558689806298224

Johnson, R. B., Onwuegbuzie, A. J., \& Turner, L. A. (2007). Toward a definition of mixed methods research. Journal of Mixed Methods Research, 1, 112-133. https://doi.org/10.1525/ sp.1960.8.2.03a00030

Lambert, Z. V., \& Durand, R. M. (1975). Some precautions in using canonical analysis. Journal of Market Research, 12, 468-475. https://doi.org/10.2307/3151100

Leech, N. L., \& Onwuegbuzie, A. J. (2007). An array of qualitative data analysis tools: A call for qualitative data analysis triangulation. School Psychology Quarterly, 22, 557-584. https://doi.org/10.1037/1045-3830.22.4.557

Leech, N. L., \& Onwuegbuzie, A. J. (2008). Qualitative data analysis: A compendium of techniques and a framework for selection for school psychology research and beyond. School Psychology Quarterly, 23, 587-604. https://doi.org/10.1037/1045-3830.23.4.587

Leech, N. L., \& Onwuegbuzie, A. J. (2011). Beyond constant comparison qualitative data analysis: using NVivo. School Psychology Quarterly, 26, 70-84. https://doi.org/10.1037/ a0022711

Levine, M., \& Thompson, K. (2004). Identity, place, and bystander intervention: Social categories and helping after natural disasters. Journal of Social Psychology, 144, 229-245. https://doi.org/10.3200/SOCP.144.3.229-245 


\section{MInstitute Macrothink $_{\text {Intion }}$}

Manly, B. F. J. (2004). Multivariate statistical methods: A primer (3rd ed.). London, England: Chapman \& Hall.

Merriam-Webster's Collegiate Dictionary (11th ed.). (2005). Springfield, MA: Merriam-Webster.

Onwuegbuzie, A. J. (2016). The missing link: The use of link words and phrases as a link to manuscript quality. Journal of Educational Issues, 2, 320-330. https://doi.org/10.5296/ jei.v2i2.9697

Onwuegbuzie, A. J., \& Combs, J. P. (2009). Writing with discipline: A call for avoiding APA style guide errors in manuscript preparation. School Leadership Review, 4, 116-149.

Onwuegbuzie, A. J., Combs, J. P., Frels, R. K., \& Slate, J. R. (2011). Editorial: Citation errors revisited: The case for Educational Researcher. Research in the Schools, 18(1), i-xxxv. Retrieved from http://msera.org/docs/RITS_18_1_Complete.pdf

Onwuegbuzie, A. J., Combs, J. P., Slate, J. R., \& Frels, R. K. (2010). Editorial: Evidence-based guidelines for avoiding the most common APA errors in journal article submissions. Research in the Schools, 16(2), ix-xxxvi. Retrieved from http://msera.org/docs/ RITS_16_2_APAErrors6th.pdf

Onwuegbuzie, A. J., \& Daniel, L. G. (2002). Uses and misuses of the correlation coefficient. Research in the Schools, 9(1), 73-90.

Onwuegbuzie, A. J., \& Daniel, L. G. (February 12, 2003). Typology of analytical and interpretational errors in quantitative and qualitative educational research. Current Issues in Education, 6(2). Retrieved from https://cie.asu.edu/ojs/index.php/cieatasu/article/view/ $1609 / 651$

Onwuegbuzie, A. J., \& Daniel, L. G. (2005). Editorial: Evidence-based guidelines for publishing articles in Research in the Schools and beyond. Research in the Schools, 12(2), 1-11. Retrieved from http://msera.org/docs/Rits_editorial_12_2.pdf

Onwuegbuzie, A. J., Frels, R. K., \& Slate, J. R. (2010). Editorial: Evidence-based guidelines for avoiding the most prevalent and serious APA error in journal article submissions-The citation error. Research in the Schools, 17(2), i-xxiv. Retrieved from http://msera.org/ docs/RITS_17_2_Citations.pdf

Onwuegbuzie, A. J., Hwang, E., Combs, J. C., \& Slate, J. R. (2012). Editorial: Evidence-based guidelines for avoiding reference list errors in manuscripts submitted to journals for review for publication: A replication case study of Educational Researcher. Research in the Schools, 19(2), i-xvi. Retrieved from http://msera.org/docs/RITS 19_2_Reference_errors2.pdf

Onwuegbuzie, A. J., Hwang, E., Frels, R. K., \& Slate, J. R. (2011). Editorial: Evidence-based guidelines for avoiding reference list errors in manuscripts submitted to journals for review for publication. Research in the Schools, 18(2), i-xli. Retrieved from http://msera.org/ docs/rits-2011-v18n2.pdf 
Onwuegbuzie, A. J., Mallette, M. H., Hwang, E., \& Slate, J. R. (2013). Editorial: Evidence-based guidelines for avoiding poor readability in manuscripts submitted to journals for review for publication. Research in the Schools, 20(1), i-xi. Retrieved from http://msera.org/docs/RITS_20_1_Readability.pdf

Onwuegbuzie, A. J., Waytowich, V. L., \& Jiao, Q. G. (December, 2006). Bibliographic errors in articles submitted to scholarly journals: The case for Research in the Schools. Academic Exchange Extra. Retrieved from http://asstudents.unco.edu/students/AEExtra/2006/12/ index.html

Provalis Research. (2014). QDA Miner (Version 4.1.12) [Computer software]. Montreal, Quebec, Canada: Author.

Pym, A. (2010). Exploring translation theories. New York, NY: Routledge.

Tabachnick, B. G., \& Fidell, L. S. (2007). Using multivariate statistics (5th ed.). Boston, MA: Allyn \& Bacon.

Tashakkori, A., \& Teddlie, C. (Eds.). (2010). Sage handbook of mixed methods in social and behavioral research (2nd ed.). Thousand Oaks, CA: Sage. https://doi.org/10.4135/978150 6335193

Vogt, W. P. (2005). Dictionary of statistics and methodology: A nontechnical guide for the social sciences (3rd ed.). Thousand Oaks, CA: Sage. https://doi.org/10.4135/9781412983907

Waytowich, V. L., Onwuegbuzie, A. J., \& Jiao, Q. G. (2006). Characteristics of doctoral students who commit citation errors. Library Review, 55, 195-208. https://doi.org/10.1108/ 00242530610655993

Wilson, K. G. (1993). The Columbia Guide to Standard American English. New York, NY: Columbia University Press.

\section{Notes}

Note 1. Onwuegbuzie, Combs, et al. (2010) extracted the following 14 themes that represented APA errors made by authors submitting manuscripts to a selected journal: grammar, format, hyphenation, citing multiple authors, in-text citations, numbers, capitalization, formality and clarity, statistical copy, punctuation, tables and figures, abbreviations, quotations, and bias in language.

\section{Copyright Disclaimer}

Copyright for this article is retained by the author(s), with first publication rights granted to the journal.

This is an open-access article distributed under the terms and conditions of the Creative Commons Attribution license (http://creativecommons.org/licenses/by/3.0/). 